Svetlana Aleksiévich, El fin del "Homo sovieticus" (Barcelona: Acantilado, 2015).

\author{
RESEÑA
}

\title{
ALEKSIÉVICH, UNA ESPÍA
}

\author{
Joaquín Trujillo Silva
}

Centro de Estudios Públicos

"Quien sufre parece que danza" Una mujer en El fin del "Homo sovieticus"1

1 cumplirse en 2017 un siglo del estridente inicio de la Revolu-
ción Rusa, ese proceso que decantó en la fundación de la Unión de Repúblicas Socialistas Soviéticas (URSS), vale la pena detenerse sobre El fin del "Homo sovieticus"2 —en adelante FHS—, la última y más extensa "novela-oratorio" de la Premio Nobel de Literatura 2015 Svetlana Aleksiévich.

FHS trata sobre el desplome de la URSS, este monumental proyecto estrictamente planificado por la burocracia del Estado moderno, que se extendió entre "Polonia y China" (289), pero - y este pero es fundamental - según la boca de sus protagonistas anónimos, porque, como ha dicho su autora, se trata de una historia doméstica.

Joaquín Trujlllo Silva. Abogado por la Universidad de Chile y magíster en estudios latinoamericanos por la misma institución. Investigador del CEP. Profesor invitado en las facultades de derecho de las universidades de Santiago y de Chile. Email: jtrujillo@cepchile.cl.

${ }^{1}$ Svetlana Aleksiévich, El fin del "Homo sovieticus" (Barcelona: Acantilado, 2015), 464. En adelante, este libro se citará tan sólo con el número de página entre paréntesis.

${ }^{2}$ El título en la edición española difiere del original — Время секонд хэнд-, que puede traducirse como "Tiempo de segunda mano". Sí, en su lugar, se asemeja al subtítulo que lleva el original: El fin del hombre rojo. "Tiempo de segunda mano" es el libro quinto y final de la serie "Voces de la utopía". Moscú: Vremia, 2013. 
El libro está dividido en dos "testamentos" subdivididos, a su vez, en diez libritos cada uno, los cuales se dejan leer de forma más o menos independiente. La primera parte, "El consuelo del Apocalipsis. Diez grandes historias en un interior rojo", reproduce una serie de testimonios, de extensión variada, tomados a personas que vivieron las épocas de Stalin, Khrushchev, Brezhnev, Andropov, Chernenko, Gorbachov y Yeltsin (21-384). La segunda parte, "El encanto del vacío. Diez historias en medio de ninguna parte" (385-638), hace lo propio con las que han vivido bajo Yeltsin, Putin, Medvedev y de nuevo Putin. El libro anexa además una cronología útil para orientar al lector en la historia reciente de Rusia, ${ }^{3}$ cronología que va desde el 5 de marzo de 1953 (fecha de la muerte de Stalin) al año 2012 (fecha de las manifestaciones contra Putin y su partido) (639-643).

Si hubiera que resumir los asuntos más trillados de este libro, habría que contar que, conforme a los testimonios, la URSS comienza a derrumbarse con una aceleración del ritmo de vida, que quiebra los esquemas de trabajo, ${ }^{4}$ mientras que su carácter imperial se resquebraja con el auge de los nacionalismos y etnicismos que convivían bajo la cúpula soviética. ${ }^{5}$ Uno de los problemas de la URSS era que, pese a los inicios "pacifistas" de la Revolución, ella se había erigido en torno a la guerra $^{6}$ y al papel ejemplar y edificante desempeñado por los cientos de héroes cuyo culto oficial se volvía insoportable para muchas personas comunes. $^{7}$ El culto al héroe explica, tal vez, una lealtad desmesurada por el régimen que aún se conserva o incluso es mayor, ${ }^{8}$ y no es raro que los ex soviéticos puedan ser descritos como niños inocentes. ${ }^{9} \mathrm{La}$

${ }^{3}$ En lo que respecta a la voz "Rusia", me ciño aquí al uso que le da Aleksiévich, que es también el de los protagonistas de FHS; es decir, se trata de un uso laxo, que a veces designa a varios de los países de la ex URSS, otras a los de la actual Federación, y que no siempre distingue a las claras a Ucrania o Bielorrusia, por ejemplo.

4 95-96, 148, 182, 387, 389, 397, 514-515, 591, 621, 637.

${ }^{5} 122,134,137,139,319,322,367,394,408,415,528,541,566,579$.

6 54-55, 167, 193-194, 199, 267, 271, 320, 363, 494, 505, 567, 561.

7 200, 247, 254, 260, 267-268, 280-281, 477-478, 495, 507, 511, 567, 573, 617-619.

8 58, 86-89, 127, 130-133, 160, 222-223, 249.

9 59, 201, 207, 286, 338, 343-345, 420, 455, 459, 468. 
URSS nació y se sostuvo en la labor de intelectuales, ${ }^{10}$ especialmente en la de oradores que poco a poco devinieron en funcionarios incapaces de hacer sobrevivir la Unión sin antes recibir órdenes. ${ }^{11}$ Entre los aspectos más sobresalientes, bien porque desmienten algunos mitos, bien porque los entrevistados no siempre se muestran decididamente adversos, están el racismo, especialmente contra judíos y gente morena; ${ }^{12}$ el orden autocrático; ${ }^{13}$ la memoria del terror; el actual terrorismo y las mafias; ${ }^{14}$ hechos entre los cuales los episodios de hambrunas son escalofriantes. ${ }^{15} \mathrm{El}$ libro asciende hacia temáticas más complejas tales como la revolución tras una fallida Revolución, ${ }^{16}$ la nostalgia del primer tiempo soviético (en contraste con el segundo, o sea, el actual). ${ }^{17}$ En las últimas páginas, alguien afirma que la Biblia dice que Dios es un Dios de amor, no de justicia, y que el problema de la URSS fue haber basado sus mejores ideales, cuando los hubo, no en el amor, sino que en la justicia. ${ }^{18}$ Finalmente, y a modo de inciso, se dice que los libros de Aleksiévich son tan terribles que es mejor ahorrarse sus penas. De acuerdo, pero FHS también cuenta con notables escenas de humor. ${ }^{19}$

Ahora bien, lo dicho hasta aquí no hace de FHS más que otro libro sobre la tragedia totalitaria, sus explicaciones y testimonios. Sin embargo, en FHS late un problema ligeramente distinto.

$1071,80,82,85,87,165-166,195-196,212,221,298,439,443,444-448$, 452-454, 458-459, 493, 495, 522, 618.

$1174,86,149,161-162,210-211$.

$12112-113,262-265,521,526-529,555$.

$13147,167-168,186,368,399-400,511,513,519$.

$14105,114,117,130-132,140,142-143,145,169,237,240,245,318,367-$ 369, 373-374, 436, 452, 462, 471, 474, 477, 482-483, 490, 491.

15 Ryszard Kapuściński, en El Imperio, recuerda junio de 1933, cuando los caminos de Ucrania se hallan repletos de cadáveres y no son "extraordinarios los casos (hoy conocidos) de mujeres, enloquecidas y ya inconscientes de sus actos, que se comen a sus propios hijos". Ryszard Kapuściński, El Imperio (Barcelona: Anagrama, 2015), 117.

$16201,208-209,115-119,210,219,233,363-364,391,393-395,398,400-$ 401, 404, 406, 445, 469, 514, 619.

${ }^{17} 67,102,125,184-185,190,207,209,224,312,360,369,393,518,526$, $536,550$.

${ }_{18} 192,214-215,227,243,288,297,315,589,591-592,597,602-603,611$.

${ }^{19} 166,173-174,176-178,186,240,506,511$. 


\section{TRANSGÉNERO LITERARIO}

A primera vista, este bíblico libro - por lo profundo y voluminoso- es uno de esos casos notables en que un subgénero minusvalorado por la gran escena literaria, como lo ha sido muchas veces la crónica periodística y testimonial, alcanza esa cima en que pasa a competir en otras ligas, consolidando a su subgénero pero a la vez superándolo.

Ahora, como el caso de otros libros de Aleksiévich, a pesar de la filiación periodística de su autora, no puede decirse que $F H S$ pertenezca a un género literario del todo reconocible. No es ni una novela de formato clásico ni una evidente crónica periodística, un poema épico de factura contemporánea o una encubierta pieza de dramaturgia. ${ }^{20}$ ¿Dónde se inscribe entonces?

Esta pregunta es en buena medida abordada por el libro mismo, el cual, a través de las voces que lo nutren, reflexiona sobre su propio género y su propio método. Por eso, en las páginas que siguen nos concentraremos en la adquisición de los testimonios, ateniéndonos al presupuesto conforme al cual Aleksiévich no ha perpetrado la operación clásica de escritura, ésa consistente en transmutar la experiencia personal y la ajena en obra propia, sino que ha intentado mantener, cuanto le ha sido posible, la obra propia como ajena. Para lograrlo, ha tenido que darse muchas licencias creativas que le han valido no pocas críticas. ${ }^{21}$

En una entrevista con Guy Chazan, Aleksiévich explica: "Existe una tradición, que se remonta a la época de Tácito y Plutarco, en la que la historia pertenece a los héroes, los emperadores (...). Pero crecí entre gente sencilla y sus historias me destrozaron por completo. Fue doloroso que solamente yo estuviera escuchándolos". ${ }^{22}$

${ }^{20}$ En su momento cúlmine de las páginas 611 y 612, el relato se vuelve, en el fondo y en la forma, definitivamente una pieza teatral.

21 Sophie Pinkham ha cotejado distintos manuscritos del libro de marras y concluido que se "queda corto como hecho y como arte", porque, ha explicado, si es fidedigno, es parcial; y si no es fidedigno, es artísticamente discreto. Véase Sophie Pinkham, "Witness Tampering”, New Republic, 29 de agosto de 2016.

22 Guy Chazan, "Nobel laureate Svetlana Alexsievich on her fears for Russia's 'collective Putin'”, Financial Times Weekend, 16 de junio de 2017. Una traducción fue publicada en El Mostrador, 25 de junio de 2017, disponible en http://www. elmostrador.cl/cultura/2017/06/25/svetlana-alexievich-ganadora-del-premio-nobelhabla-sobre-su-miedo-del-putin-colectivo/. 
Hay, sin embargo, otra vieja tradición de la creación occidental, una que está centrada precisamente en la escucha, pero en la de personas sin importancia, un verdadero espionaje de lo insignificante. La describió, en parte, el poeta ruso Osip Mandelstam - muy mencionado en FHS - cuando explicaba que Dante Alighieri construyó su universo de personajes, salvados muchos del olvido en la Divina Comedia, prestando atención incluso a las voces más postergadas por cuanto fisiológicamente defectuosas. ${ }^{23}$ En esta tradición parece inscribirse $F H S$, ésa de la escucha, de la insustituible palabra dicha no tanto por conocidos, sino que principalmente por extraños. Es ése, por lo demás, el emblema de Anna Ajmátova, amiga de Mandelstam en el grupo de los acmeístas (otra de las grandes menciones en FHS), que en el epílogo de su poemario Réquiem explicaba cómo ese gran poema había sido tramado: "He aquí una gran manta para ellas tejida / de pobres palabras de ellas oídas". ${ }^{24}$ Así, en FHS, María, por ejemplo, una mujer que de niña sufrió la deportación, explica: "Soy una esclava de las palabras... Tengo una fe absoluta en ellas... Siempre escucho las palabras que pronuncian las personas con las que me encuentro y también las de los desconocidos. De hecho, las palabras de los desconocidos me interesan aún más"; un testimonio clave, ars factum de este libro (307). Eso, en cuanto al método de Aleksiévich, que parece absuelto por una voz ajena a la suya.

En cuanto a su forma, la escritura de Aleksiévich no está sometida al formulario-tipo de los géneros literarios estancos; es una escritura que simula traspasarnos los materiales crudos de la creación literaria, antes de haber sido transubstanciados por los escritores, los editores, los críticos y reseñistas. Es más, Aleksiévich prefiere estas voces, según ha confesado: "¿Por qué inventar héroes cuando las cosas que estas personas dicen son mucho mejores?"25 En ellas no habla un trasfondo objetivo, esa norma prestigiosa del hablar científico; habla, en cambio, la parcialidad roída. Así, la escucha y la escritura de Aleksiévich se fusionan a un punto en que se hace difícil, cuando no imposible, distinguir qué es lo que ella reproduce y qué lo que ella misma produce.

${ }^{23}$ Osip Mandelstam, Coloquio sobre Dante (Barcelona: Acantilado, 2004), 73 : "Tengo la impresión de que Dante estudió muy detenidamente todos los defectos del habla, que prestaba atención a los tartamudos, a los ceceosos, a los gangosos, a quienes no pronunciaban claramente algunas letras, y que aprendió mucho de ellos".

${ }^{24}$ Anna Ajmátova, Réquiem (Madrid: Mondadori, 1998), versos 9-10.

${ }^{25}$ Chazan, "Nobel laureate". 
Aleksiévich abrió los oídos a las voces de la calle, las oficinas de provincia, las compañías de viaje en tren (451) - así, tal cual El idiota, de Dostoievski-; a las conversaciones ajenas en los bares, y especialmente a la evocación de aquellas que, según explica, socavaron desde sus entrañas el imperio soviético: las conversaciones en las cocinas (142). ${ }^{26} \mathrm{Su}$ trabajo consiste en mantener los oídos dilatados y la grabadora a mano "para poder captar así el momento del tránsito de la vida, de la vida más simple, a la literatura, un momento que siempre vigilo tanto en las conversaciones particulares como en las corales", aunque a veces, agrega, se distrae, deja el acecho y se le escapa el "pedacito de literatura" (509). Como nuestro Nicanor Parra, Aleksiévich sabe y practica la máxima según la cual la alta —y la baja— poesía sale a ratos de las bocas de las personas; sólo hay que andar expectante para atraparla en el aire. Con todo, los contextos de captación se vuelven espinosos: "No hay historias hermosas en las bambalinas... Allí todo está oscuro y sucio", dice Olga (295), una de sus entrevistadas. Una inmigrante tayika - etnia cuyos miembros, en Moscú, viven mayoritariamente en el subsuelo de la ciudad $-{ }^{27}$ cuenta que ha tenido un sueño en el que intentaba extraer, de entre las espinas de un cardo, un sedoso algodón. Este sueño es una suerte de metáfora de todo FHS. Aleksiévich parece darnos a entender que de entre las espinas de este libro terrible, a veces, y si se lo hace con cuidado, es posible extraer información preciosa. ${ }^{28}$

26 "Todo el país vivía en las cocinas... En las cocinas de nuestras casas o las de nuestros amigos nos reuníamos a beber vino, escuchar música, hablar de poesía... Con una lata de conserva y un poco de pan negro... Y todos nos sentíamos a gusto" (210). El consumo al interior de esas cocinas significó todo un foro político, que se perdió al caer la URSS y migrar dicho consumo a las ofertas que trajo el capitalismo consigo. Véanse las páginas 36, 143, 147, 188, 201, 214, 221-223, 269 , 270-273, 275, 383, 432-434, 451, 457, 467-468, 514, 516-518, 521, 526, 562, 565, 591,600 .

${ }^{27}$ Habitantes de Tayikistán, ex república de la URSS. Los tayikos son una etnia irania de lengua persa. En la gran ciudad se ocupan de los trabajos más básicos, son los habitantes tras esas bambalinas del desperdicio y, en la historia de la URSS, sufrieron las bambalinas de la geopolítica.

${ }^{28}$ La belleza - que, como hemos ya adelantado, es un principio de extracción en este libro - tenía también un lado menos de ensueño, muy práctico: "Irás al infierno de los campos...", le dicen a una mujer. "Pero eres guapa, así que le caerás en gracia a uno de los jefes y salvarás la vida" (302). Otras veces, emerge de episodios en extremo gratuitos. La escritora María Voiteshnok recuerda que en su infancia de completa miseria, un día llevó con su hermana un chal de plumón a una 
En cuanto a sus objetivos, digamos que Aleksiévich intentó y consiguió una obra monumental sobre la vida de los seres comunes en y después de la Unión Soviética, una colección de cientos de testimonios que, se hace preciso aclarar, no siguen en su conjunto ninguna agenda política: "Quiero ser una historiadora que actúe imparcialmente, sin empuñar ninguna antorcha encendida", declara (98), haciéndonos pensar que, a pesar de las luces que rechaza, ella es una exhumadora de la luz en las vidas humanas mismas, entre los duetos, tríos, quintetos que se suceden en su "novela polifónica". La mayoría son verdaderos monólogos que recuerdan a los shakespereanos, brechtianos o beckettianos (por darles parentescos reconocibles en la tradición literaria); otros son bravuconadas gritadas al mundo, genuinas confidencias apenas susurradas al vaivén en un viaje en tren u oyendo el traquetear de los trenes que pasan. Hay en FHS testimonios de pequeños funcionarios provinciales, de ancianas que vivieron la guerra, de hijos e hijas que hablan del mutismo de sus progenitores o del suyo propio. Confiesa Olga Karímova, una música de 49 años, antes de dar su testimonio:

No, no puedo... No puedo hacer esto. (...) Siempre pensé que algún día tendría que contarlo (...) Pero no ahora. (...) Lo tengo todo sellado, clausurado (...) bajo un sarcófago de hormigón, como la central de Chernóbil. ${ }^{29}$ Todavía no ha cesado la reacción nuclear adentro, aunque el fuego ya se haya apagado. Se están formando cristales. Y temo tocarlos. (281)

Otra de las voces, Tamara Sujovei, de 29 años, al hablar siente "como si lavara una olla" (550). La sinceridad es una presa esquiva

mujer acomodada. Ellas vestían harapos y la mujer les dijo: "Dejadme que os corte unas flores", y se las colgó. María dice: "Vivíamos soñando con mendrugos y aquella mujer supo percibir que también éramos capaces de anhelar algo más” (309). Ése quizá sea su consuelo porque, como ella misma dice: "La gente suele recordar mejor la belleza que el dolor" (309). La belleza opera disuadiendo en situaciones violentas. Madre e hija van a una protesta en la actualidad: "Mi madre es actriz y tiene setenta y cinco años. Compramos un par de ramos de flores previendo que la situación pudiera tornarse violenta. ¡No irían a disparar contra dos mujeres cargadas de flores!” (401).

${ }^{29}$ El primer libro traducido al español de Aleksiévich fue Voces de Chernóbil, una colección de potentes testimonios de personas que estuvieron relacionadas con el accidente nuclear en la planta ucraniana. 
cuando se ha vivido bajo el control de la opinión y el del fuero interno. "Ni siquiera entre nosotros hablábamos en el frente con franqueza", dice un veterano de la Segunda Guerra (258). "Tú cierra bien la boca y no le cuentas nada a esa mujer", advierte una madre llorando a su hija que se reunirá con Aleksiévich (618). Se trata de un problema que acosa a todo escritor o escritora que ha alcanzado algún renombre: la vida ya no se le presenta como a un simple mortal, la vida se le presenta distorsionada; ya no hay vida real para quien se sabe que mira. Y cuando se trata de recabar testimonios, la dificultad puede ser mayor si hay contextos de temor a la censura social; a la larga, la franqueza sufre el desprestigio del desuso: "Si dices la verdad nadie te cree, pero basta que digas mentiras para que te consideren una persona estupenda" (593). Con el terror las dificultades empeoran: "Hay muchas cosas que no recuerdo... ¡No quiero recordarlas! ¡No quiero!", confiesa Ksiusha, una veinteañera que ha sido víctima del terrorismo y cuyo novio ha roto con ella cuando le ha confesado su episodio traumático: "Comprendí que me iría mejor si me ahorraba las confesiones" (476 y 483). Esto parece la segunda parte de aquella tesis de Isak Dinesen, repensada por Hannah Arendt, según la cual la narración es el comienzo de la sanación. ${ }^{30}$ "En realidad, no es a usted a quien quería contarle todo esto, sino a mí misma...", le dice una publicista exitosa (470). La pregunta que aquellos tres puntos sugiere y que quizá por decoro Aleksiévich no formula, es: ¿puede contárselo a sí misma?

La gente común, que ha padecido sin consuelo literario, a veces no alcanza a entender qué es exactamente lo que pretende Aleksiévich con sus investigaciones. Como le dice un ex soldado: "Eso nadie se lo contará (...). Esas cosas no son un juego, ni son literatura” (507). En esa misma línea, están quienes ven en el género intentado por Aleksiévich un peligro social. Le confiesa un ex alto hombre del Kremlin, testigo de la muerte del mariscal Ajromeiev:

He leído los libros que usted ha publicado y creo que hace mal en confiar tanto en el hombre, en la verdad que pueda comunicarle

${ }^{30}$ Para más detalles, véase el artículo de Lynn R. Wilkinson, "Hannah Arendt on Isak Dinesen: Between Storytelling and Theory", Comparative Literature 56, n. ${ }^{\circ}$ 1 (2004): 77-98. 
un hombre... La historia recoge la vida de las ideas. Y no son los hombres quienes la escriben, sino el tiempo. Las verdades que manejan los hombres son como esos clavos en los que cualquiera puede colgar un sombrero. (163)

Pero la historia es aquel relato que ha sido establecido desde la óptica del Estado, y FHS se trata precisamente de reconocer la vida en los confines del Estado soviético. Así, otra entrevistada es la escritora de 57 años María Voiteshonok. Ella era una osadnitsa, ${ }^{31}$ lo que de alguna forma explica el que en la actualidad ignore la fecha de su nacimiento: "En la historia de mi vida todo tiene un carácter aproximado... Y no he dado con una base documental que la cuente. A veces existo y a veces no" (304). De ahí que éste sea uno más de sus libros en que Aleksiévich insiste en la importancia de las verdades parciales, contradictorias entre sí, de las que emerge una extraña sensación de certeza y que la historia oficial, en su pretensión panóptica, no cobija: "Toda persona es digna de una película de Hollywood", dice la documentalista Irina Vasílieva (597), un alter ego de Aleksiévich que recorre Rusia con su cámara. Y es que en este libro cada ser humano es una conciencia digna de atención, a la cual el todo histórico no reemplaza, incapaz de pensar en lugar de ella. "Un árbol o un animal del bosque no tiene noción del tiempo. Dios se ocupa de pensar por ellos", es lo que afirma Volodia Pidbotski, un condenado a cadena perpetua por haber matado a un hombre (608). Los seres humanos no deben permitir que la historia piense sus vidas por ellos mismos. Los sentimientos son difíciles de subsumir en una historia general. "No sé por qué lloro, si la historia de mi vida me la conozco al dedillo...", dice Anna Maya, otra de las mujeres que dan su testimonio (348).

$\mathrm{Y}$ es que la idea de una sola verdad es contraria a este libro. "Mi último deseo es que usted escriba la verdad. Ni la suya ni la mía... pero que se escuche mi voz", le dice un viejo comunista (233). Pero lo que él no entiende es que la "verdad" y la "voz" no son enteramente compatibles. Aleksiévich tiene a la voz por prioridad. Sin embargo, hacia el

${ }^{31}$ Es decir, un miembro de la población polaca a la que se adjudicó tierras en los territorios que Rusia perdió ante Polonia en 1921, pero que luego, con el tratado secreto Molotov-Ribbentrop firmado entre la URSS de Stalin y la Alemania de Hitler en 1939, quedaron bajo dominio soviético, de lo que resultó la deportación de los osadnikis. 
final del libro, las palabras de la documentalista son reveladoras: "En nuestro pragmático mundo todavía hay personas cuya existencia se rige por una lógica singular". Sus historias propias, es cierto, son extrañas como la lógica que rige sus vidas, mas "en cada una de esas historias está contenido todo" (590).

\section{DRAMATURGIA HECHA DE TESTIGOS ANÓNIMOS}

FHS está recorrido por escenas en que las propias fuentes testimoniales piden a gritos que todo quede por escrito. "Ahí va el tren", le dice a Aleksiévich Marina Tíjonovna Isaichik, una mujer solitaria. "Ése, el que sale de Brest a Moscú. Aquí no necesito reloj. Me levanto con el pitido del tren de Varsovia, a las seis en punto de la mañana. Y después pasan el de Minsk y el primer tren a Moscú... No pitan igual el de la mañana y el de la noche. A veces me paso la noche en vela escuchando el paso de los trenes" (109), y añade: “¿Lo estás anotando todo? Tú escribe, jescribe! Te contaré más cosas" (110).

Además, hay desahogos que parecen infértiles. "Contar esta historia tantas veces acabará matándome... No sé por qué lo hago una y otra vez", confiesa la madre de la sargento de policía Olesia Nikoláieva, que ha muerto en Chechenia. No cree que el libro que proyecta escribir Aleksiévich —es decir, FHS - pueda ayudarla. Cree que será un libro que leerá "gente buena": "La gente mala, que es a quienes en verdad concierne todo esto, lo pasará por alto" (558-559).

Según ese mismo espíritu, en el escalofriante cierre de la primera parte de FHS, su autora recibe el testimonio de un hombre a quien le ha tocado conocer la confesión en confianza de un verdugo del NKVD, ${ }^{32}$ un hombre que se bañaba en perfume después de intensas jornadas de torturas y asesinatos para arrancarse el olor a sangre. ${ }^{33}$ Es un cliché decir que la historia la escriben los vencedores y no los vencidos, pero este hombre le explica a Aleksiévich lo poco que se sabe del mal que de

32 El Comisariado del Pueblo para Asuntos Internos (NKVD, sigla de Naródny Komissariat Vnútrennij Del) estuvo activo entre 1934 y 1954, coincidiendo con las épocas más crudas del control estalinista.

33 "Las manos se nos embadurnaban tanto de sangre que teníamos que secar las palmas frotándolas contra nuestro propio cabello", le habría relatado ese ex miembro del NKVD (377-378). 
cierta manera ha resultado exitoso: "Las víctimas son las que cuentan sus historias, las que quedan aquí para hablar, pero los verdugos... Los verdugos callan. Escurren el bulto, se esconden en su agujero. (...) Los verdugos no dejan huella. No sabemos nada de ellos" (375). En efecto, FHS es un libro en el que hablan las víctimas o, con mucho, los cómplices. Aleksiévich apenas pudo acceder a los verdugos.

$F H S$, una recopilación de testimonios que tardó décadas, se abrió paso a pesar de que, su autora, muchas veces debió aguardar autorizaciones de sus fuentes, que se arrepentían a último momento o tras haber hablado demasiado. Estarán, además, quienes callaron porque pensaban que sus historias eran inverosímiles. En una de las pocas ocasiones en que Aleksiévich se manifiesta en el texto, Margarita, una armenia de Azerbaiyán que logró sacar su relación amorosa adelante en medio de la guerra étnica (su marido era azerí), pregunta a la autora si ella cree su historia. "La creo (...)", dice Aleksiévich, "crecí en el mismo país que usted, ;claro que la creo!", y ambas se echan a llorar (427).

El problema del testimonio, que Aleksiévich recoge de la boca de la documentalista Irina Vasílieva, es el después de. "He querido contar todo esto muchas veces. Me iba de la lengua a cada rato. Pero nadie me preguntó después de escucharme: 'Y luego, ¿qué?'” (318). De ese luego el libro intenta hacerse cargo -Aleksiévich les sigue la pista durante años a muchos de sus personajes-, pero no en todos los casos. La naturaleza del libro documental es tomar una parte. ${ }^{34}$ Además, con el acopio de testimonios crudos, va ocurriendo que muchos de ellos se vuelven casi triviales por reiterativos que sean. Hay escenas de $F H S$ que, con el correr del libro mismo, van haciéndonos perder el grado de asombro. "Ya hace mucho tiempo que dejé de ser una idealista... Porque ahora sé demasiado", dice una mujer (530). Con todo, FHS se esfuerza por impedirnos, en tanto lectores, perder el asombro. En esto, la disposición de las historias a través de sus 600 y tantas páginas es un logro notable que Aleksiévich dio a la organización del material.

En lo que concierne al tipo social del entrevistado, los hay muchos, pero llama la atención que sea la Rusia profunda la que transita por

${ }^{34}$ Aleksiévich ha publicado versiones revisadas de sus libros en las que incluye información nueva sobre sus personajes, por lo que ha sido acusada de flagrantes contradicciones. Véase Pinkham, "Witness Tampering". 
las páginas de $F H S$. En términos de la cultura musical, que nos es más familiar, FHS no trata sólo de la Rusia de Prokosiev o Shostakovich, ni, si ahondamos, la de Giorgy Sviridov o Pavel Chernonov; ésta es también la Rusia de los fans de Tatiana Bulanova o la más conocida Alla Pugacheva (cantante superventas, famosísima en la URSS de la segunda mitad del siglo XX y en sus actuales ex repúblicas), que aparece mencionada varias veces. La instalación del capitalismo fue muy dura para muchos rusos. "Ladrones" y no capitalistas los llaman. En una conversación, en que las invectivas contra los nuevos ricos aparecen a cada instante, un hombre dice que el capitalismo en Rusia "no ha conseguido extenderse más allá de Moscú" (395). "Eh, Moscú, dime si te da igual que te quieran o que te odien", tatarea para sí Aleksiévich (543). Y es que, como se ve en el libro, Moscú no es Rusia. "Vemos en la televisión las noticias de Moscú como quien ve una película", dice una mujer de la provincia. Aleksiévich, por lo tanto, dedicó buena parte de FHS a escuchar esa Rusia que los occidentales no conocemos y que algunos rusos tampoco, aquella Rusia profunda de campo, de "casuchas a medio caer rodeadas de empalizadas hechas añicos. Perros y gallinas vagando perdidos por todas partes. Alcohólicos haciendo cola delante de la tienda de licores ${ }^{35}$ todavía cerrada", que es como la describe la documentalista Vasílieva, que a la postre, agrega: "Un paisaje tan familiar que te produce náuseas. Y, por supuesto, el busto de Lenin orondo, en el centro de la aldea" (591), todavía hoy.

Un aspecto que llama poderosamente la atención en todos los personajes de FHS, con escasas excepciones, es que, una vez rota la cortina de hierro del primer contacto, hablan y hablan, desmedidamente locuaces como tantos personajes de Dostoievski, que a través de cientos de páginas parecieran sufrir de incontinencia verbal. Aleksiévich marca las pausas con escuetas descripciones entre paréntesis — por ejemplo, " $(\mathrm{Ca}-$ 1la)"- Pero si bien es cierto que aquellas pausas psicológicas tan chejovianas son muchas, no es menos cierto que el lector las pasa por alto, tal vez porque éste es un libro no de descripciones a ojo desnudo, sino que de escuchas de su autora, como la más sensible de las espías, autora que

${ }^{35}$ En la Rusia post Gorbachov, dicen algunos testimonios de FHS, los habitantes de los campos "se beben cualquier cosa que arda" (144), vecinos que por lo caro del vodka beben agua de colonia, alcohol de cocinar, detergente (115). 
apenas se deja ver u oír por el lector ${ }^{36}$ (casi nunca anota las preguntas que hizo, sino que hace como si los entrevistados se interrogasen a sí mismos). Así, creo no pecar de temeridad al proponer que se trata de una obra dramatúrgica; es decir, una que oculta todo lo que puede la voz personal de su autora. No es casual que se la haya acusado de preparar a sus testigos, e incluso, agreguemos aquí, fabricar falsos monólogos.

\section{LOS ARCHIVOS EN EL CIELO}

FHS es un gran ejercicio de denuncia, pero también de esa memoria universal de lo particular a la que apelaba Anna Ajmátova cuando reproducía en su Poema sin héroe el emblema en el palacio de los Sheremetyev "Deus conservat omnia"; 37 esto es, Dios conserva todo, porque es él el gran archivero. "Hay un lugar donde se guardan todas nuestras lágrimas", dice uno de los personajes de FHS (111), como parafraseando las Bienaventuranzas (Mateo 5: 3-11). El padecimiento aparece relacionado también con un valor más allá de esa garantía extramundana de preservación: "Cuando pasa cierto tiempo, el dolor se transforma en una especie de conocimiento", explica Olga (284).

En lo que a la insoslayable polémica política respecta, el libro de Aleksiévich no persigue objetivos ordinarios; no pertenece a aquel género de denuncia que, a la larga, es leído por lectores afines que buscan justificar sus propias convicciones. Éste es un libro que no permite ese ejercicio como tampoco solventar teorías del empate. Se trata de una dramaturgia escrita para "un tiempo que no conocerá nuestras preferencias" (98), en la que los personajes cuentan sus experiencias con la fuerza propia de la parcialidad.

Para terminar, refirámonos al destino, también humano, que era lo que la URSS buscaba y a la vez diseñaba.

Un tiempo después de convertirse en el primer homo sapiens en emerger al espacio exterior, el cosmonauta Yuri Gagarin se precipitó a

${ }^{36}$ Esta regla de escritura decae un poco en las últimas cien páginas del libro. Una excepción la encontramos a propósito de unas entrevistadas, madre e hija, que habían sobrevivido al atentado terrorista de 2004 en el metro de Moscú. Aleksiévich, como nunca, se explaya sobre sus sentimientos: "A veces pienso que el dolor es un puente que une a las personas, un lazo secreto, y otras veces, desesperada, pienso que el dolor es un abismo que las separa" (471).

${ }^{37}$ Véase capítulo 35 de Harrison E. Salisbury, The 900 days. The Siege of Leningrad (Cambridge: Da Capo Press, 2003). 
tierra durante un vuelo rutinario de avión. Gagarin era de origen campesino. Se cuenta que fue preferido a German Titov, el otro cosmonauta, que actuó de suplente suyo, en razón del activo publicitario que la URSS veía en enviar a un campesino al espacio, símbolo del logro revolucionario que consistía en pulverizar el clasismo de la historia humana. El físico y precursor ruso Konstantín Tsiolkovski, en una carta de 1911, había escrito: "Un planeta es la cuna de la mente, pero no se puede vivir en la cuna para siempre" (a lo cual Hannah Arendt responderá que el ser humano huye desde el mundo al yo y desde la Tierra al Universo). ${ }^{38}$ Por su parte, Gagarin salió de la cuna, dentro, eso sí, de una especie de cuna, o, mejor dicho, una placenta metálica. Como en una tragedia griega, pese a su hazaña, el destino de Gagarin era caer, volver al fondo.

Con todos sus horrores, la URSS, la más campesina y por lo tanto la menos apta de las sociedades europeas para la hazaña socialista, subió junto con Gagarin y cayó. ¿Qué tanta diferencia hizo en el viejo homo sapiens el "homo sovieticus"? Puede tratarse de algo menos grandilocuente. Tal vez, en el contexto de la gran historia de la humanidad, de sus largas transformaciones y proyectos frustrados, la URSS sea como aquella canción popular de 1981 de la cantante Alla Pugacheva, "Как Тревожен Этот Путь" (“Cuánta dificultad en el camino"). En ella se habla sobre el intento de emprender un viaje: el camino lucirá lleno de dificultades, de incomodidades, el sendero apenas se verá, no se sabe si se pueda completar, quizá convenga abortar el viaje, tal vez sea mejor volverse a casa, al calor del hogar donde vive la seguridad y desistir de ese empeño. "Yo no engaño mi destino (...) / No podré ver desde arriba / cómo acaba este camino", 39 dice la canción. Este libro es una inmensa colección de testimonios sobre el regreso al planeta Tierra de un proyecto utópico, y Svetlana Aleksiévich actúa como la espía que nos ha hecho llegar el mensaje de quien, atónito, sube desde lo profundo, vuela alto y cae. EP

${ }^{38}$ Hannah Arendt, "Prólogo", en La condición humana (Buenos Aires: Paidós, 2013).

39 Videoclip disponible en https://www.youtube.com/watch? $\mathrm{v}=\mathrm{S} 3 \mathrm{kR} 7$ nuvbiY. Agradezco a la brillante abogada rusa Liya Khanipova por haberme ayudado con esto. 